\title{
Aspergillosis in African Grey Parrot (Psittacus erithacus) in Private Aviary, Meerut, India
}

\author{
Shailja Katoch, Harshit Verma*, Akshay Garg and Rajeev Singh
}

Department of Veterinary Microbiology, College of Veterinary \& Animal Sciences

S. V. P. University of Agriculture \& Technology, Meerut, 250110, Uttar Pradesh, India

*Corresponding author

\section{A B S T R A C T}

\section{Keywords}

African grey parrot, Aspergillosis,

Aspergillus flavus,

Streptococcus spp.

Article Info

Accepted:

12 January 2019

Available Online:

10 February 2019
The present study describes acute Aspergillosis in a five years old female African grey parrot kept in captivity in Meo Aviary, Meerut. The birds in the aviary were housed in uplifted cage system and vaccinated against endemic diseases. The affected bird exhibited the symptoms of depression, anorexia, dyspnea and open beak breathing and died within 48 hours of showing clinical signs. At necropsy, whitish nodules were observed on the trachea, lungs and air sacs. The affected organs were collected for cultural isolation of the possible organism. Aviary visit indicated dusty environment. Aspergillus flavus and Streptococcus spp. were isolated from the samples collected at necropsy. Damp and dusty environment and moldy feeds must be avoided and adequate ventilation should always be provided in aviary to prevent aspergillosis.

\section{Introduction}

Aspergillosis is a common infectious but noncontagious, life threatening fungal disease of captive birds (Atkinson and Brojer, 1998; Faucette et al., 1999). It is mainly caused by Aspergillus fumigatus but less frequently Aspergillus flavus, Aspergillus niger, Aspergillus nidulans and mixed infections involving bacteria and viruses have also been reported (Joseph, 2000). The Aspergillus spp. are ubiquitous soil saprophytes that thrives best on organic matter under humid conditions at temperature upto $25^{\circ} \mathrm{C}$
(Flammer, 2002). They are opportunistic pathogens and cause disease in immunocompromised host under stressful conditions or when the host is exposed to large number of spores (Stone and Okoniewski, 2001). Aspergillosis is reported worldwide in different forms with cutaneous, respiratory, ocular and nervous signs (Leishangthem et al., 2015). Diagnosis of the infection is carried out by recording the clinical signs, necropsy examination and fungal isolation. The present study was carried out to investigate aspergillosis in African grey parrot and its predisposing factors. 


\section{Materials and Methods}

The case history and clinical signs were considered carefully before attempting necropsy examination. Physical appearance of the carcass and the gross morbid visible lesions of organs and tissues were recorded. From the dead parrot the affected tissues were collected aseptically for microbiological isolation and cultured on solid media using standard methods.

\section{Microbiological examination}

The microbiological investigations were carried out in the Department of Veterinary Microbiology, College of Veterinary and Animal Sciences, SVPUA\&T, Meerut. The samples were inoculated on 5\% Sheep Blood agar (BA), MacConkey lactose agar (MLA) and Sabouraud dextrose agar (SDA) and incubated aerobically at $37^{\circ} \mathrm{C}$ for $24-48$ hours for bacterial growth and $25^{\circ} \mathrm{C}$ for 5-7 days for fungal growth. The organisms were identified using conventional bacteriological and mycological methods.

\section{Results and Discussion}

The affected bird exhibited the clinical symptoms of depression, decreased appetite and ruffled feathers (Fig. 1). On visual examination the bird was alert, but was showing difficulty in breathing with open beak breathing and gasping. The bird died within 48 hours of showing clinical signs. The necropsy examination revealed the diffuse whitish nodules on trachea and lungs which varied in size from miliary to large nodules (Fig. 3). The air sacs were thickened and their internal surface was covered with diffused whitish nodules. On Blood Agar pin point, beta haemolytic, greyish and glistening colonies were observed whereas no growth was observed on MLA plate.

The organism appeared in chains and was Gram positive in morphology. On biochemical examination these Gram positive organisms showed negative reaction to catalase, oxidase, VogesProskaur and urease tests and confirmed as Streptococcus spp. On Sabouraud dextrose agar (SDA) plate greenish yellow growth appeared on fourth day (Fig. 2). The culture was stained with lactophenol cotton blue and showed septate hyphae with long conidiophores of A. flavus on microscopic examination (Fig. 4) (40X). Aspergillosis is one of the most common mycotic infections found in birds (Kunkle, 2003).

Fig.1\&2 African grey parrot showing signs of dullness and open beak breathing \& Nodular formation in the lungs of a grey parrot
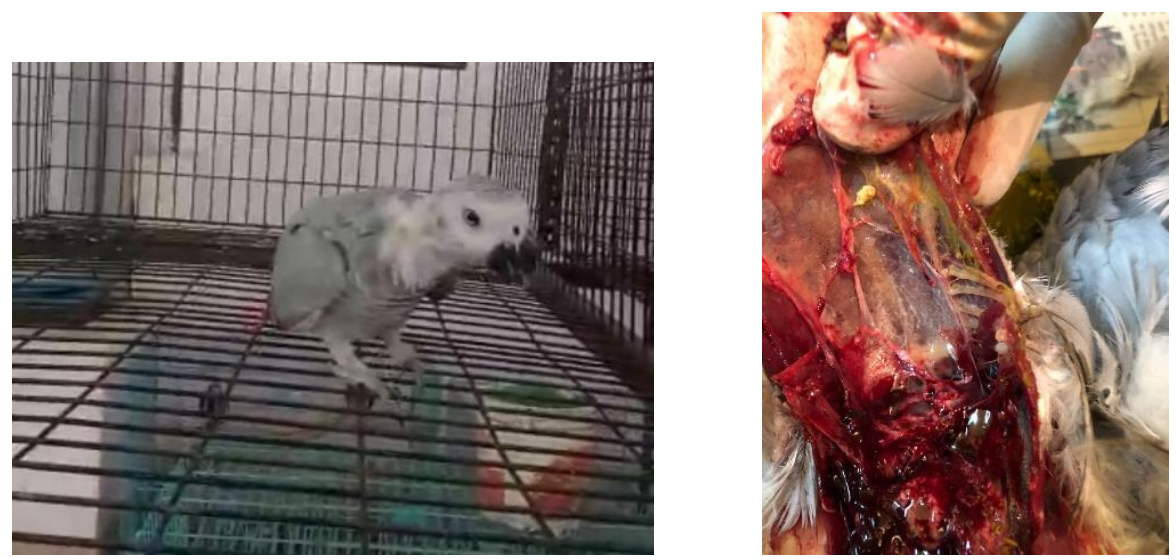
Fig.3 Greenish yellow colonies of Aspergillus flavus on Sabouraud Dextrose Agar

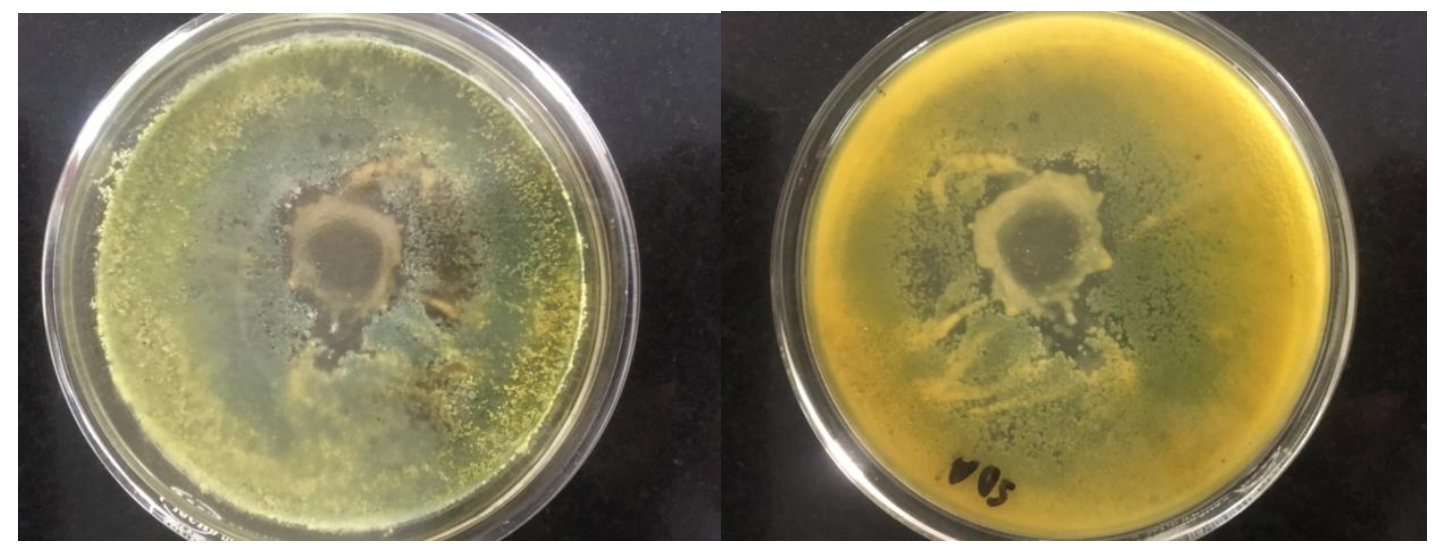

Fig.4 Microscopic observation of Aspergillus flavus

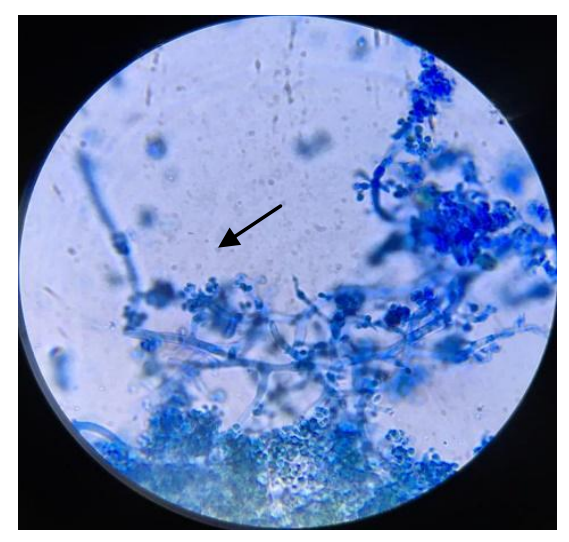

All avian species are susceptible but infection is of clinical significance in captive waterfowl, wading birds, penguins, raptors, pheasants, passerines, and some species of psittacines (Oglesbee, 1997; Kunkle, 2003). In addition to species susceptibility, immunosuppression, stress, malnutrition, vitamin deficiency, long term use of antibiotics, poor ventilation, poor sanitation and concurrent infections act as predisposing factors (Redig, 1993). A single birds or flocks of different avian species may be affected with acute or chronic forms of this disease (Beernaert, 2010; Arne et al., 2011). In the present study aspergillosis was recorded in acute form in private aviary birds. The infection with Streptococcus spp. and dusty environment were the predisposing factor leading to clinical aspergillosis. The infection in only single bird of the flock supports the fact that it is a noncontagious disease. The clinical findings of dyspnea, gasping and hyperpnea and necropsy findings of fungal nodules or plaques are in agreement with the previous findings of Kunkle (2010) and Munir et al., (2017). Based on this case report, it is advised that the African grey parrot or companion birds should be reared under good husbandry practices with strict vigilance on predisposing factors which determines the risk of aspergillosis in birds. To the authors' knowledge, there are in numerable worldwide reports about mycotic pneumonia due to Aspergillus spp. infection in psittacine birds, this is the first report describing pulmonary aspergillosis caused by A. flavus infection in Psittaciformes. Aspergillosis is neither contagious disease nor zoonotic in nature, but with the continuous exposure to polluted surrounding sources of Aspergillus spp., both birds and humans could develop an acute infection in the respiratory system. 
However, no information about possible Aspergillus spp. infection cases among the people of the aviary from where the parrot was imported is revealed. After this observation no further mortality happened in that private aviary.

\section{Acknowledgement}

The authors are highly thankful to the Hon'ble Vice-Chancellor, Sardar Vallabhbhai Patel University of Agriculture \& Technology, Meerut for providing necessary facilities for the work.

\section{References}

Atkinson, R. and Brojer, C. 1998. Unusual presentations of aspergillosis in wild birds. Proceeding of Association Avian Veterinary. 8:177-181.

Faucette, T.G., Loomis, M., Reininger, K., Zombeck, D., Stout, H., Porter, C. and Dykstra, M. J. 1999. A Three-year study of viable airborne fungi in the North Carolina Zoological Park R.J.R. Nabisco Rocky Coast Alcid Exhibit. J. Zoo Wildlife Med. 30:44-53.

Joseph, V. 2000. Aspergillosis in raptors. Seminars in Avian and Exotic Pet Medicine. 9: 66-74.

Flammer, K. 2002. Diagnosis and management of avian aspergillosis. Proceedings of the North American Veterinary Conference, Small Animal Edition, January, Orlando, Florida. 16:848-850.

Stone, W.B. and Okoniewski, J.C. 2001. Necropsy findings and environmental contaminants in common loons from New York. J. Wildlife Dis. 37:178-184.

Leishangthem, G.D., Singh, N.D., Brar, R.S. and Banga, H.S. 2015.Aspergillosis in Avian Species: A Review. J. Poul. Sci. Tech. 3:01-14.

Kunkle, R. A. 2003. Fungal infections. In: Diseases of poultry, 11th ed. Barnes HJ, Glisson JR, Fadly AM, McDougald LR and Swayne DE. (eds.) American Association of Avian Pathologists, Iowa State University Press, Ames, IA. pp. 883-902.

Oglesbee, B.L. 1997. Mycotic diseases. In: Avian medicine and surgery, 1st ed. Altman RB, Clubb SL, Dorrestein GM and Quesenberry K. (eds.) W. B. Saunders Co., Philadelphia, PA. pp. 323331.

Redig, P. T. 1993. Avian aspergillosis. In: Zoo and wild animal medicine, current therapy 3. Fowler ME. (ed.) W. B. Saunders Co., Philadelphia, PA. pp. 178-181.

Arne, P., Thierry, S., Wang, D., Deville, M., Loc'h, G. L., Desoutter, A., Femenia, F., Nieguitsila, A., Huang, W., Chermette, R. and Guillot, J. 2011.Aspergillusfumigatus in poultry. Int. J.Micro. 746356.

Beernaert, L. A., Pasmans, F., Van, Waeyenberghe, L., Haesebrouck, F and Martel, A. 2010. Aspergillus infections in birds: a review. Avi. Path. 39: 325-331.

Munir, M.T., Rehman, Z.U., Shah, M.A. and Umar, S. (2017). Interactions of Aspergillus fumigatus with the respiratory system in poultry. Worl. Poul. Sci. J. 73: 321-336.

Kunkle, R.A. 2010.Aspergillosis. In: Kahn CM and Line S., (eds.) The Merck Veterinary Manual. $10^{\text {th }}$ edition. Whitehouse Station, NJ: Merck Publishing, pp: 2497-2498.

\section{How to cite this article:}

Shailja Katoch, Harshit Verma, Akshay Garg and Rajeev Singh. 2019. Aspergillosis in African Grey Parrot (Psittacuserithacus) in Private Aviary, Meerut. Int.J.Curr.Microbiol.App.Sci. 8(02): 1480-1483. doi: https://doi.org/10.20546/ijcmas.2019.802.172 